Int. J. Dev. Biol. 64: 383-391 (2020)

https://doi.org/10.1387/ijdb.190312mb

\title{
The human face: genes, embryological development and dysmorphology
}

\author{
MEENAKSHI BHAT* \\ Centre for Human Genetics, Bengaluru, India
}

\begin{abstract}
Clinical dysmorphology is a medical specialty which requires training to systematically observe aberrations in facial development and to understand patterns in the recognition of underlying genetic syndromes. An understanding of normal facial embryology and structure, genetic mechanisms that contribute to facial development and the influence of age, sex, epigenetic, environmental and teratogen effects that contribute to facial dysmorphology are essential. The role of software programmes and databases in achieving diagnoses in subtler phenotypes is growing. A description of specific dysmorphisms of various parts of the human face and key genetic and mechanistic pathways are discussed in this review. Recognizing facial patterns and genetic syndromes efficiently aids in planning appropriate tests, securing an accurate diagnosis, counselling and predicting outcomes and offering interventions and therapies where available.
\end{abstract}

KEY WORDS: human facial dysmorphology, gene, embryology

"Who sees the human face correctly: the photographer, the mirror or the painter?"

Pablo Picasso

Picasso probably did not suspect that a keen dysmorphologist supported with an armamentarium of genetic investigations could possibly be as keen a contender in recognition of human facial features. A constellation of features that consistently appear together in a particular syndrome helps in identification of a specific gestalt (e.g. Down syndrome, velocardiofacial syndrome) (Donnai, 2009). A clinical dysmorphologist is trained to recognize facial phenotypes in the diagnosis of a genetic syndrome or a syndrome in a specific genetic pathway (eg. Noonan variants in RAS-MapKinase pathway). With over 7000 genetic disorders described, many with subtle facial variations, the role of computer programs using 2D and 3D facial profiling in identifying an appropriate match has been discussed in recent literature (Claes, 2014; Dudding-Byth et al., 2017; Gurovich et al.,2019). Research groups from India have also described the use of computer based digitization of images in the accurate description of syndromes like Rubinstein Taybi MIM\#180840 (Dalal, 2007) and in surgical management of unilateral cleft lip and palate (Harikrishnan, 2018). The utility of recognizing facial dysmorphology as ascribed to a syndrome emerges from the fact that many of these syndromes are accompanied by a varying degrees of intellectual disability and some with progressive neuro-disability. Early and accurate recognition of the facial gestalt is helpful in choosing the most appropriate test/s for confirmation of diagnosis and institution of early intervention and therapies.

Embryogenesis of the human face begins around 4 weeks of gestation before a woman realizes that she is pregnant. The complex processes that govern facial development in humans result in a unique pattern of features. Delineation of the facial phenotype is important in many sciences: anthropological, forensic, police and immigration profiling, facial aesthetics, neuroscience and in clinical genetics. This review will highlight some of the embryological and genetic processes and their influences or interruptions in development, which result in a particular facial phenotype or a dysmorphic syndrome. Syndrome recognition is done by experts in dysmorphology by clinical observation and often aided by computer programmes such as Face2Gene, Possum and others.

Facial shape and form is orchestrated by an exquisitely timed cascade of developmental genes, signaling molecules and transcription factors, environmental influences including nutrition and geography as well as epigenetic modulation (Fig. 1).

In humans, the face develops mainly from specialized neural crest cells and the process occurs between the $4^{\text {th }}$ and 8 th week of gestation (Marcucio et al., 2015). In the $4^{\text {th }}$ week the neural crest derived mesenchyme develops five primordial elevations seen

Abbreviations used in this paper: FGFR, fibroblast growth factor receptor.

*Address correspondence to: Meenakshi Bhat. Centre for Human Genetics, Biotech Park, Electronic City Phase I, Bengaluru 560100, India.
E-mail: bhat.meena@gmail.com -Tel: +91 80 28521831/32 - (iD) https://orcid.org/0000-0002-3867-8250

Submitted: 7 October, 2019; Accepted: 28 October, 2019.

ISSN: Online 1696-3547, Print 0214-6282

(c) $2020 \mathrm{UPV} / \mathrm{EHU}$ Press

Printed in Spain 


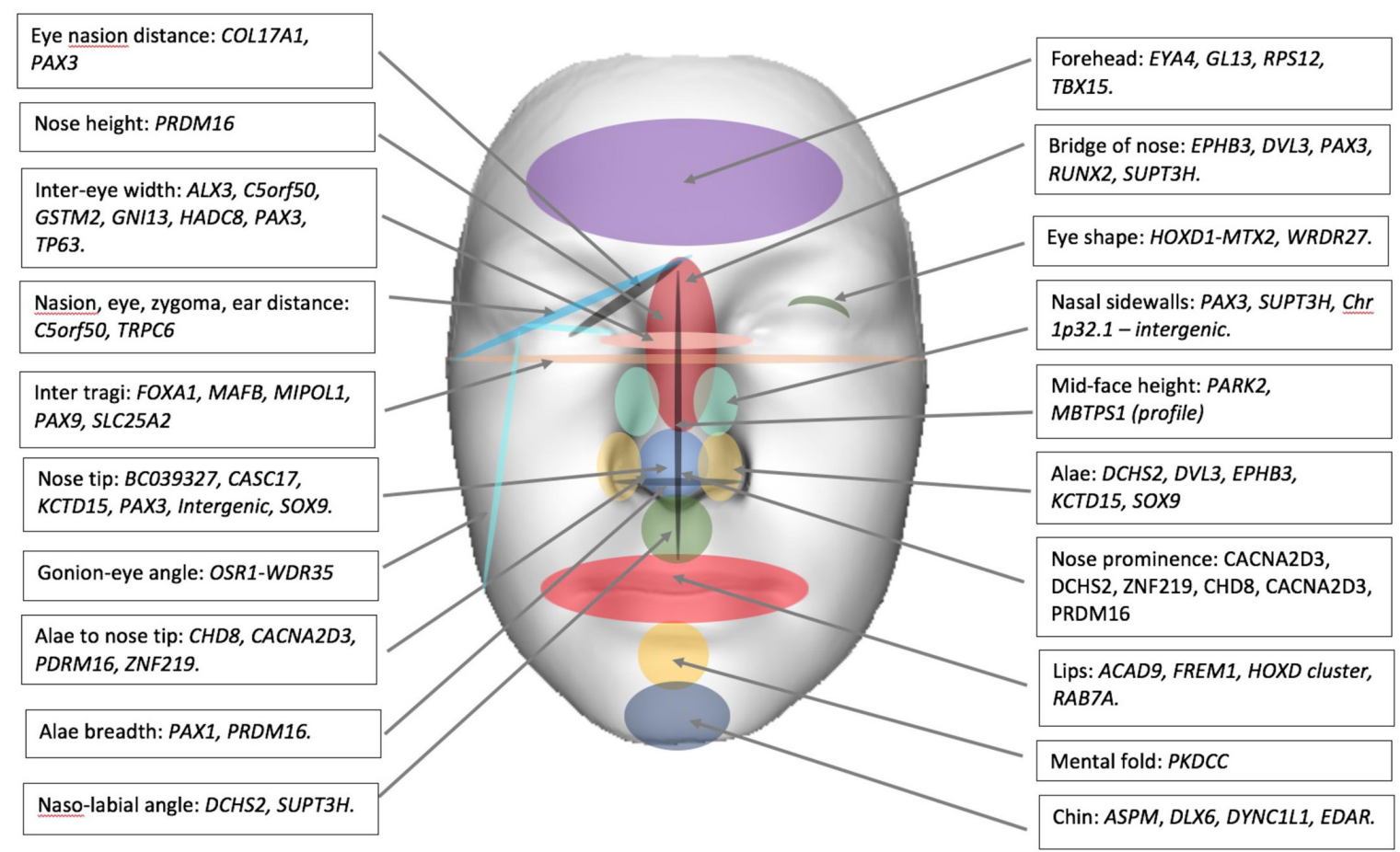

Centroid size: SCHIP17; Allometry: PDE8A Upper facial profile prominence: $P C D H 15$
Fig. 1. Gene association with regionalised facial features in normal populations. Taken from: RICHMONDS., HOWEL.J., LEWISS. STERGIAKOULI E., ZHUROV A. (2018). Facial Genetics: A Brief Overview. Front Genet 9: 462. Licence: CC BY 4.0 around the stomodeum (these are the frontonasal prominence, paired maxillary and paired mandibular prominences). At the cephalic end of the embryo, the frontonasal process will eventually form the forehead, upper eyelids and conjunctivae. At the top of the frontonasal process are two nasal placodes. Behind and to the side of these are the developing optic discs. There are three paired branchial arches which form on either side. The first arch divides into an upper maxillary and a lower mandibular prominence. Between the $5^{\text {th }}$ and $6^{\text {th }}$ week, nasal development proceeds with

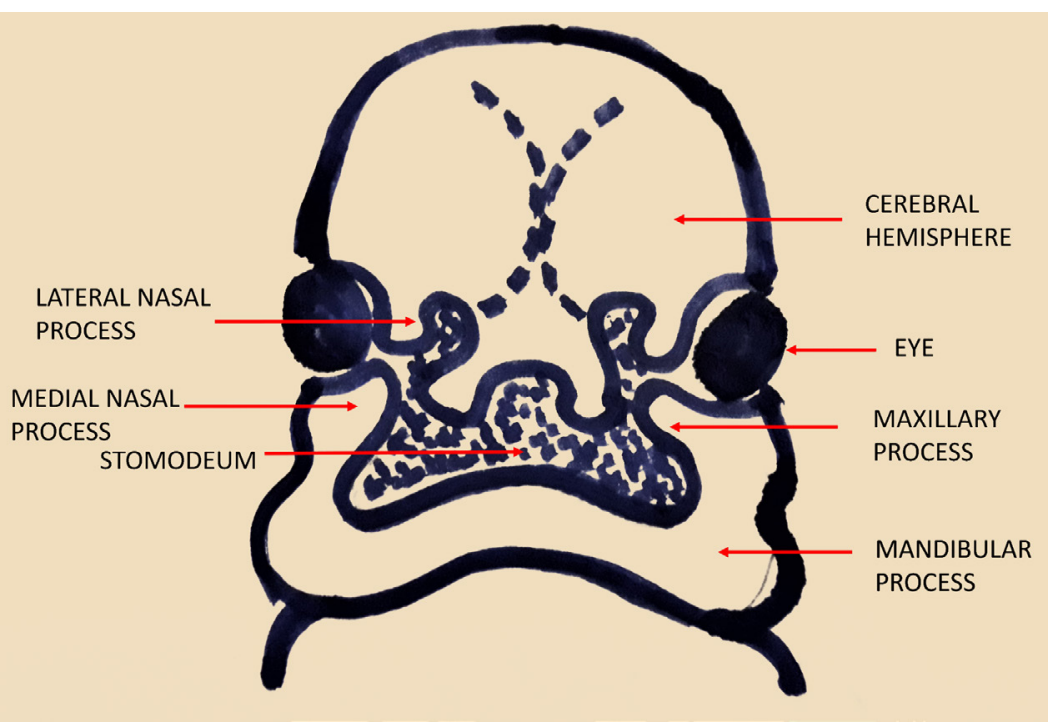

Fig. 2. Cartoon depicting frontal view of human embryonic face between 6-7 weeks gestation. formation of nasal pits, migration to a more central position and fusion with the maxillary process. The lens vesicle invaginates and becomes enclosed in the optic disc. In the $6^{\text {th }}$ week the formation of the jaw (maxillary process) and the auricle of ear begin from the mandibular and hyoid ( 2 nd branchial arch) prominences. At the end of the $7^{\text {th }}$ week, the face take a recognizable shape with formation of eyelids, medial and lateral nasal prominences and formation of the ear pinna (Fig. 2).

From the eighth week onwards till the end of pregnancy, the shape of the face gradually changes to assume its final appearance with the formation of the forehead, medial movement of the eye sockets and upward migration of the ears, all in response to the growth of the underlying brain.

Although the human face is a composite of several sense organs, each with a clear function, the size and pattern of these organs, their location in the face, any deviation from the normal or the presence of an extra organelle, tissue, structure or pigmentary lesion may help in defining a unique feature linked to a particular syndrome. When the shape of the face is altered in a syndrome, the examiner's eye tends to focus on the most distinctive abnormality as the key feature upon which to build a search. More often a systematic cephalo-caudal evaluation of descriptive and measurable anomalies in the face and elsewhere in the body associated with clinical experience enables one to make a clinical diagnosis. Confirmation by appropriate genetic studies is often the concluding step in diagnosis. In this review, a small number of illustrative examples are used to highlight involvement of one or more parts 
of the face. This is by no means a comprehensive anthology of facial dysmorphisms but a summary of some special situations in syndrome specification.

\section{Craniosynostosis and the shape of the head}

Embryological contribution towards formation of skull bones is thought to be from both the cranial neural crest cells and paraxial mesoderm and begins between 23-26 day post-fertilization (Lattanz et al., 2017). Premature fusion of one or more cranial sutures causes craniosynostosis, altering the shape of the head and, sometimes, the underlying brain (Fig. 3).

Compensatory overgrowth of the skull occurs in a direction perpendicular to the fused suture. Strictly speaking, craniosynostoses do not directly alter facial morphology but may result in secondary dysmorphology in the form of facial asymmetry, triangular or tower shaped skull, proptosis of eyes and shape and size abnormalities of the ear. The prevalence of craniosynostosis is reported to be 1 in $1400-2100$ with a rising frequency of cases noted in recent years (Wilkie et al., 2017). The most widely studied genes responsible in the causation of both syndromic and non-syndromic craniosynostosis are the fibroblast growth factor receptor genes (all of which have a common ancestral origin). The commonest of these, FGFR2 and FGFR3 have an association with increased paternal age and may account for the increasing frequency of craniosynostoses in some societies. This is believed to be due to germline mosaicism in testicular tissue with a positive selection for the gain of function mutations causing syndromic or non-syndromic craniosynostosis (Twigg et al., 2015).

Premature fusion of one or more sutures have implications for both aesthetic as well as intellectual purposes (because of mechanical effects on the developing brain). Since the first report of MSX2 in association with craniosynostosis (Jabs etal., 1993), over 57 human genes had been identified till 2015 (Twigg et al., 2015) and a further 39 genes since then in the causation of over 170 syndromic or non-syndromic types of craniosynostosis (Lattanz et al., 2017; Goos, 2019). Mutations in just six genes (FGFR2, FGFR3, TWIST1, EFNB1, TCF12 and $E R F)$ account for over $75 \%$ of all cases with craniosynostoses (Wilkie et al.,2017). A recent Indian GWAS study using multiple bioinformatic tools to analyze sequences in known genes demonstrated comprehensive prediction of causative variants and pathways in both syndromic and non-syndromic craniosynostosis (Barik et al., 2018). The most frequently affected are the sagittal sutures, followed by metopic and coronal sutures. Of the more recent genes implicated in midline sutural defects (metopic and / or sagittal synostosis) is SMAD6 which works through the bone morphogenetic protein (BMP) pathway. Heterozygous mutations in SMAD6 have often been reported in an affected child and an apparently unaffected parent. One explanation for this incomplete penetrance is likely to be di-genic inheritance. SMAD6 gene muta- tion positive individuals were sequenced for a previously reported single nucleotide polymorphism (SNP) rs1884302 located in the vicinity of BMP2gene (Timberlake et al., 2016). Midline synostosis affected individuals were found to harbour the high risk allele in this SNP and unaffected family members had the low risk allele/s supporting digenic inheritance from two components of the BMP pathway. SMAD6 mutations are also associated with bicuspid aortic valves and ascending aorta dilatation, raising the question whether all affected patients with craniosynostoses should be screened for cardiac defects (Yassine et al.,2017).

\section{Eyebrows}

Facial hair has reduced considerably in the modern human as compared to his ancient ancestors. The purpose of eyebrows existing has been discussed in a number of previous studies: an 

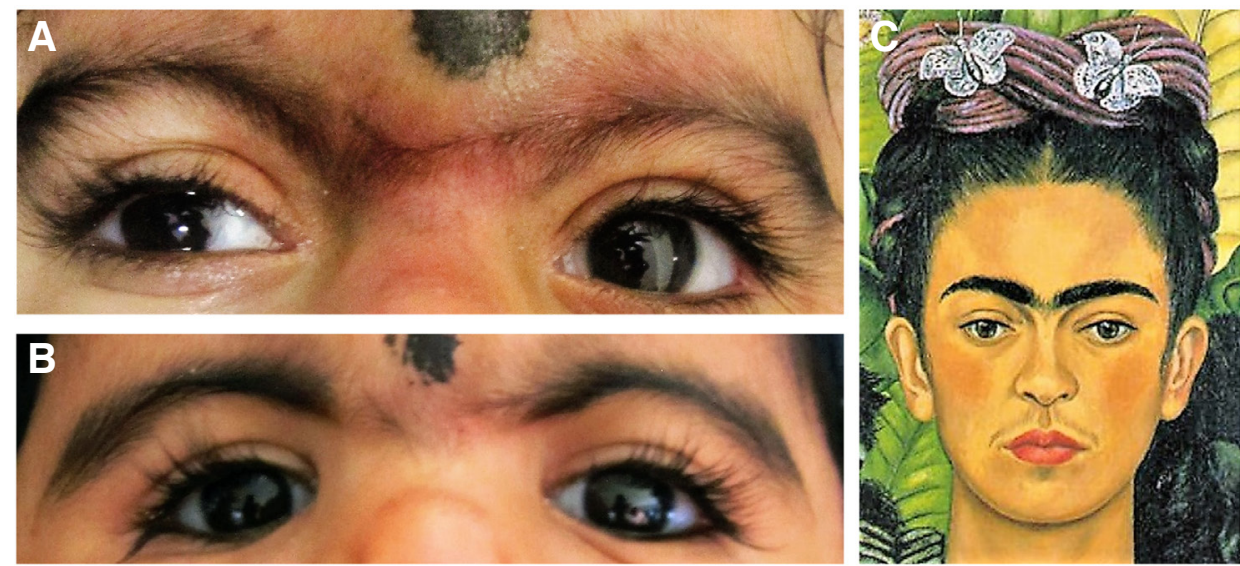

Fig. 4. Eye findings in Cornelia de Lange syndrome. (A,B) Unibrow or synophrys of eyebrows seen in Cornelia de Lange syndrome and (C) in self portrait of noted artist Frida Kahlo. Frida Kahlo self portrait from: Cuba si.com: Friday, May 13 2016. (Author's own patients, reproduced with permission).

evolutionary remnant of facial hair, a shelf like projection that provides modest protection from fluids streaming into eyes, an aesthetic part which can be modified to enhance facial attractiveness or an important instrument of facial expression (Sadr et al., 2003). Very few studies have focused on the inheritance of eyebrow patterns (Rozprym, 1934, Devi I, 1959). Most of these observational studies among distinct ethnic groups describe patterns which are similar between parents and offspring suggesting a dominant pattern of inheritance. One of the most distinct eyebrow patterns is when the two eyebrows meet medially at the glabella of the nose: referred to as synophrys (or unibrow). Synophrys is a recognizable feature in a number of genetic syndromes, most notably Cornelia de Lange syndrome MIM\#122470 (Fig. 4).

Multiple genes, all members of the Cohesin complex have been implicated in the causation of severe and milder forms of Cornelia de Lange syndrome. Synophrys or unibrow can occur in otherwise normal individuals albeit with generalized hirsutism (Kumar P, 2017). Indeed a self-portrait of the famed Mexican artist Frida Kahlo highlights her unibrow and facial hirsutism, reminiscent of mild Cornelia de Lange syndrome. In 2016, a genome-wide association study (GWAS) looking for genes responsible for facial features reported that the gene linked to unibrow was $P A X 3$ which is also important
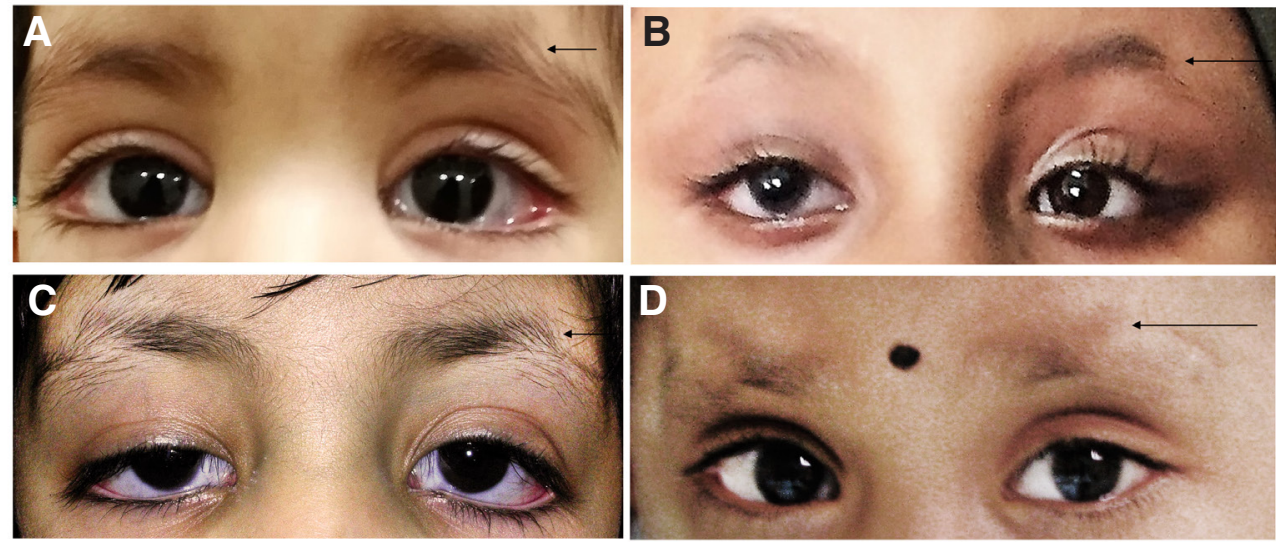

Fig. 5. Interrupted and laterally sparse eyebrows in Kabuki syndrome in four separate individuals. (Author's own patients, reproduced with permssion). for the patterning of the nasion or glabella (also discussed later) (Adhikari etal., 2016). There are many other syndromes where a distinct eyebrow pattern forms a part of the recognizable phenotype consistently, such as straight eyebrows in chromosome 1 p36 microdeletion and the interrupted eyebrows of Kabuki syndrome MIM147920 (Fig. 5), but the exact mechanisms for these patterns are not determined.

\section{Nose}

A genome wide association study (GWAS) of facial features in around 6000 Latin American individuals showed that certain genetic markers were linked significantly with the shape of the nose (Adhikari et al., 2016). These included DCHS2, GLI3, RUNX2 genes which are associated with inclination of nasal tip and breadth of the nose wing and tip respectively. The tip of the nose and the alae nasi are derived from the medial nasal segment. DCHS2 itself is involved in nasal shape by stacking of chondrocytes and also acts through its effects on SOX9a expression (Le Pabic, 2014). Heterozygous mutations in SOX9 are known to cause Campomelic dysplasia MIM\#114290, a rare systemic skeletal disorder which affects both bone and cartilage by disruption of COL2A1 gene (Bell et al.,1997).

The nasal bridge or root is between the two eyes and the width of this part: also called the nasion is determined by $P A X 3$ (Paternoster, 2012). Heterozygous mutations in PAX3 cause Waardenburg syndrome Type 1 (WS1) MIM\#193500. WS1 is an autosomal dominant disorder causing dystopia canthorum (lateral displacement of the inner canthus of the eye), segmental hypopigmentation of face and hair and bilateral deafness (Fig. 6). Waardenburg syndrome Type 2 (WS2) MIM\#193510 which is caused by mutations in MITFgene can have all other features seen in WS1 but does not manifest with widely spaced eyes (Liu, 1995). The widening of the nasion causing dystopia canthorum occurs due to PAX3 mutations and is a consistent recognizable feature in WS1.

Bi-allelic mutations in TONSL gene encoding a key scaffold protein involved in DNA replication were recently described in a very rare skeletal disorder with the acronym SPONASTRIME spondyloepimetaphyseal dysplasia in a cohort of affected Indians and Koreans (Chang et al., 2019). The main dysmorphic finding present in all affected was a depressed nasal bridge with a short upturned nose. This distinct facial feature along with short stature is key in recognition of an otherwise rare disorder.

\section{Oro-facial clefting}

Facial clefts affect 1.2/1000 live births, with isolated cleft lip and cleft lip and palate being the commonest 


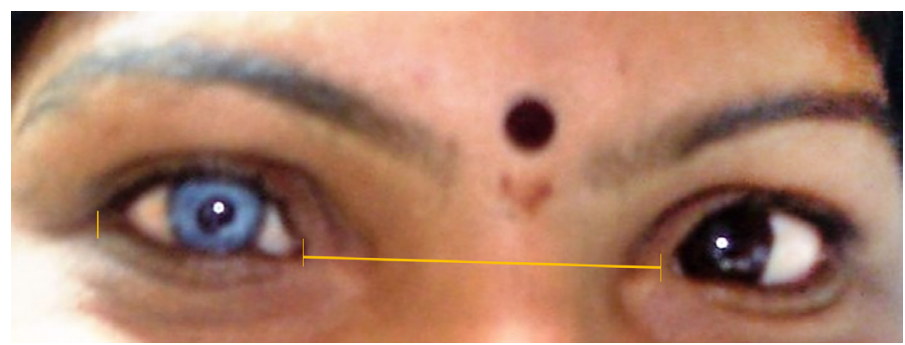

Fig. 6. Waardenburg syndrome Type I due to PAX3 mutation with heterochromia irides. Note the increased distance between the two medial canthi of the eye marked by the horizontal yellow line (dystopia canthorum). Normally the width between two eyes is equal to the size of one eye from medial to lateral canthus (marked by two yellow vertical bars). (Author's own patient, reproduced with permission).

of these defects. Over 3,300 years ago, the Egyptian pharaoh Tutankhamun, whose mummy was studied extensively after its discovery in the $20^{\text {th }}$ century was found to have a cleft palate and scoliosis. One of his stillborn daughters also had a cleft palate and other anomalies (Hawass, 2010). Hailing from a highly inbred family, it is not difficult to imagine that the Pharaoh and his daughter were the earliest examples of inherited oral clefting. It is estimated that approximately $15 \%$ of all clefts are syndromic with cleft palate being more frequently associated with a syndromic aetiology (Mossey, 2012). Of the multiple genes responsible for midline facial clefts, one of the most important is $\mathrm{SHH}$ (sonic hedgehog). Enhanced activity of the SHHpathway results in hypertelorism, a broad nasal root and midline clefting known as fronto-nasal dysplasia. This is caused by truncation of the primary cilia on the cranial neural crest cells (Brugmann et al., 2010). Conversely, decreased activity of the SHHpathway results in midface narrowing and holoprosencephaly.

Smith Lemli Opitz syndrome (SLOs) MIM \#270400 is an autosomal recessive metabolic disorder caused by mutations in $D H C R 7$ gene. DHCR7mutations affect cholesterol biosynthesis and cause SLOs, a multisystem disorder with microcephaly, structural brain anomalies, intellectual disability, cleft palate, digital and genital abnormalities. Recent studies have shown that intermediaries of cholesterol biosynthesis alter intracellular Sonic Hedgehog

\begin{abstract}
ALX1 mutation: severe mid oro-facial clefting caused by failure of fusion of the fronto-nasal and maxillary processes
\end{abstract}

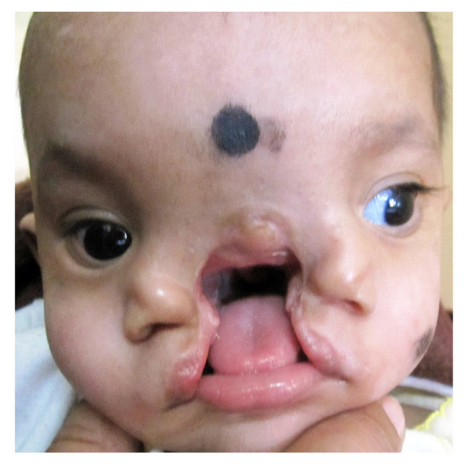

ALX3 mutation in frontorhiny: hypertelorism, a wide nasal bridge, bifid tip of nose, prominent philtral ridges and midline cleft of the upper lip

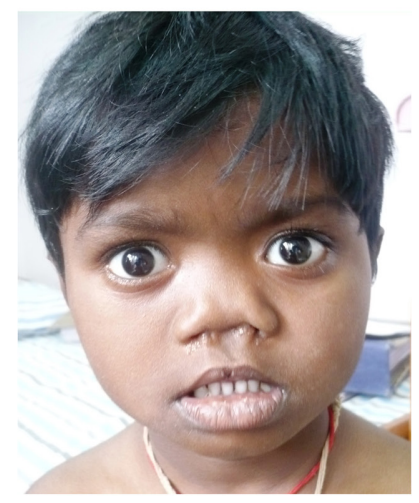

(SHH) signal transduction (Stottmann et al., 2011). Through the deleterious downstream effects of SHH mutations on the primary cilium, various craniofacial malformations, including microcephaly, holoprosencephaly and cleft palate may occur.

Several studies have suggested that timing of the disruption as well as gene dosage are jointly responsible for facial widening or narrowing. Distinctive dysmorphic syndromes with widening of midface include frontorhiny $\mathrm{MIM}^{*} 606014$ ( $A L X 3$ gene), Craniofronto-nasal syndrome (Ephrin-B1 gene) MIM\#304110 and frontonasal dysplasia (Six2 gene), some of which are seen depicted in the Fig. 7.

Autosomal recessive frontonasal dysplasia Type 1 (FND1) also called frontorhiny is caused by mutations in $A L X 3$ gene. Normally, $A L X 3$ protein is expressed in the craniofacial neural crest derived mesenchyme. Bi-allelic mutations in $A L X 3$ manifest with hypertelorism, a wide nasal bridge, bifid tip of nose, prominent philtral ridges and a midline cleft of the upper lip (Twigg et al., 2009). ALX1 mutations cause frontonasal dysplasia type 3 (FND3)MIM*601527 with severe mid oro-facial clefting caused by failure of fusion of the fronto-nasal and maxillary processes. Surprisingly for such an extensive defect, intellectual functioning is minimally affected (Umair et al., 2018). Subtyping the frontonasal dysplasias (FND; OMIM 136760 ) based on genetic aetiology has been found to be important in predicting clinical severity and prognosis (Wu et al., 2007).

Cranio-fronto-nasal syndrome (CFNS) is an X-linked condition which, interestingly has more severe manifestations in affected heterozygous females than in hemizygous males. The causative gene EFNB1 encodes a transmembrane protein Ephrin-B1 which interacts with tyrosine kinase receptors to cause bidirectional signalling. These signals result in multiple cellular functions including adhesion, migration and midline fusion as well as neural development. Heterozygous mutations in females are thought to cause cellular interference of signalling due to random $\mathrm{X}$-inactivation resulting in a more severe phenotype in females (Makarov, 2010). The resulting syndrome presents with an asymmetric skull shape, hair abnormalities, premature fusion of cranial sutures, widely placed eyes, bifid tip of nose and grooved nails, while males may have only hypertelorism (wide spaced eyes). Mosaic mutations in EFNB1 affecting males have also been reported with a more severe phenotype than in hemizygous males, supporting the theory of cellular interference (Twigg et al., 2013). A similar mechanism of cellular interference is also seen in a different condition called EFMR or epilepsy and mental retardation restricted to females caused by $P C D H 19$ gene mutations resulting in more severe epileptic encephalopathy in affected females (Sadleir, 2016).

Over 600 genetic syndromes have cleft lip with or without cleft palate (CLP) as an accompanying feature.

Fig. 7. Oro-facial clefting in various syndromes. (Patients diagnosed by author, reproduced with permission). 
With regard to syndromic cleft lip and palate, the commonest is van der Woude syndrome MIM\#119300 accounting for $2 \%$ of all individuals with CLP (Jugessur et al., 2009; Stuppio et al., 2011). Van der Woude syndrome is an autosomal dominant disorder presenting with lip pits or lumps on the lower lip (present in two thirds) and CLP caused by mutations in IRF6 gene. Interferon regulatory factor- 6 is a transcription factor and the resulting protein is expressed in the end of the paired palatal shelves before and during their fusion and is also expressed in skin. Incomplete penetrance, highly variable expression and lower than expected recurrence in close relatives also suggests the effect of modifier genes. A sequence variant in the highly conserved SMIR domain of IRF6 gene (present in $22 \%$ Asians and $3 \%$ Caucasians) is believed to be responsible for variation in the phenotypic features of this syndrome. (Kondo et al., 2002)

\section{Mouth}

Oro-facio-digital syndromes (OFDS) are a heterogenous group of inherited disorders in which at least 16 different genes are implicated and may be as rare as 1 in 50,000-250,000 births (Bruel et al., 2017). The common clinical features seen in the majority are: midline cleft or pseudo-cleft of the upper lip, multiple oral frenulae, lingual hamartomas, dental abnormalities and polydactyly in one or more limbs (Fig. 8).

Additionally, structural abnormalities of the heart, kidney or brain may also occur. A distinctive and specific clinical feature is the lingual hamartoma seen in several subtypes. Lingual hamartomas are benign, asymptomatic, whitish overgrown mature leiyomyomatous tissue seen at the base or side of the tongue (Fadzilah et al., 2016). While it can be an isolated finding, it is usually associated with various subtypes of OFDS. Causation in the majority of types is by ciliopathy genes involving primary cilia structure and function. It is not clear though whether ciliary dysfunction can explain all the phenotypic effects seen in this disorder and if $\mathrm{SHH}$ function is found to be deranged in some cases.

\section{Chin and mandible}

Epigenetic modulation of human facial development has been alluded to in many studies. A detailed atlas of tissue specific regulatory sequences important in craniofacial development has recently been published. This study profiles non-coding variants throughout the genome with functional data and chromatin activity which enrich enhancers of oro-facial clefting in early embryonic life and influence human face patterning and shape in later embryonic period (Wilderman etal., 2018). Cranio-facial abnormalities affecting the jaw bone or mandible alter the shape of the lower part of the face. The shape of the mandible appears to be highly influenced by effects of non-coding regulatory elements. Two very similar rare hyperostotic disorders, sclerosteosis and van Buchem disease present with a broad jaw and skull abnormalities, the sclerotic deformity of the skull causing progressive compression of cranial nerves, pain and neurological abnormalities. The majority of cases of sclerosteosis have been described in Europeans, however a recent southern Indian study reported both autosomal recessive and dominant slerosteosis in Tamil Nadu with likely founder mutations in SOST and LRP4 genes (Whyte et al.,2018). While sclerosteosis, the more severe recessive disorder was found to be caused by homozygous mutations in the SOST gene encoding sclerostin, the cause of van Buchem disease remained elusive. More recently, a recurrent homozygous $52 \mathrm{~Kb}$ deletion in non-coding DNA $35 \mathrm{~Kb}$ downstream of SOST gene was reported in all patients of van Buchem disease (Loots et al., 2005) suggesting a distant regulatory sequence influencing a gene underlying an important dysmorphic craniofacial syndrome. Further studies narrowed the evolutionarily conserved region ECR5 within the $52 \mathrm{~Kb}$ region as being the bone growth enhancer. Better knowledge of the role of this regulatory mechanism may be exploited in developing a therapy in commoner diseases such as osteoporosis.

In contrast to the broad jaw of van Buchem syndrome, Pierre Robin sequence (PBS) comprises of a triad of features: micrognathia (small jaw), cleft of the median palate and glossoptosis (posteriorly placed tongue). Inherited PBS may be isolated or part of a Mendelian disorder such as Stickler syndrome, velocardiofacial syndrome and campomelic skeletal dysplasia. In some familial cases of familial PBS, a breakpoint was noted in Chromosome 17q24. This was located between two important genes SOX9 gene (implicated in campomelic dysplasia) and KCNJ2. The area between these two genes has highly evolutionary conserved regions. Reduced expression of mRNA in both SOX9 and KCNJ2 in such cases suggest a distance effect on one or both genes in the causation of PBS (Jakobsen, 2007).

Another interesting condition affecting the mandible is Treacher Collins syndrome MIM\#154500. First described highlighting its eye manifestations (Collins, 1933), this syndrome features a downward slant of eyes with a characteristic coloboma of the lower eyelid, ear deformities, hypoplastic mandibular rami, micrognathia, a wide mouth, cleft palate and normal intellect in the majority. Heterozygous mutations in TCOF1 gene encoding Treacle protein are implicated in nearly two thirds of affected individuals (Vincent et al., 2016). Most pathogenic mutations cause loss of protein function and/ or haploinsufficiency. Recent studies report that haploinsufficiency in TCOF1 results in re-localization of DDX21 (a RNAhelicase) from the nucleolus to nucleoplasm which in turn activates p53 gene based
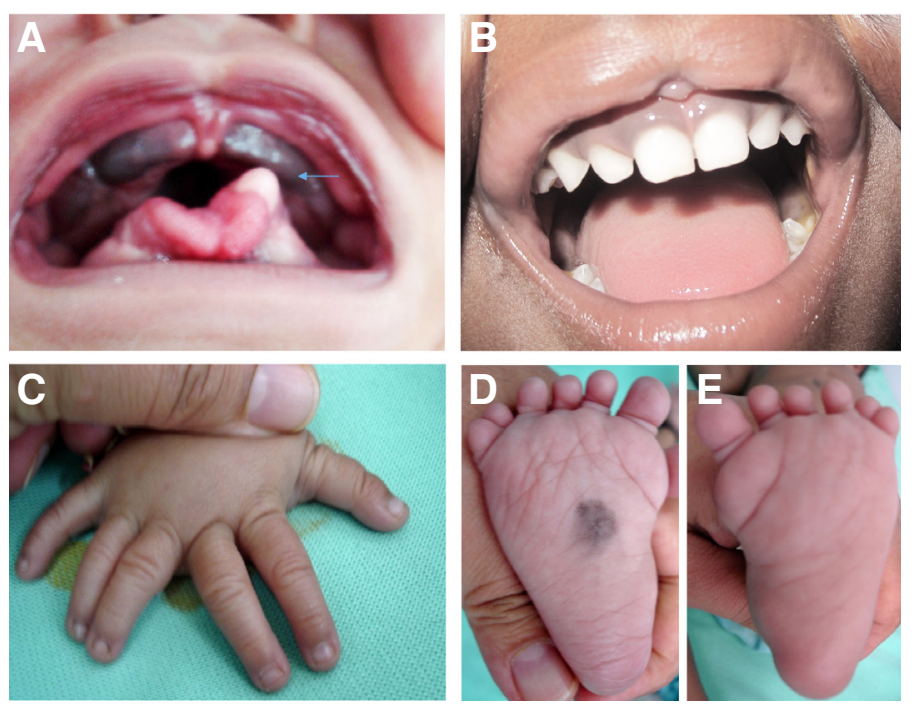

Fig. 8. Oro-facio digital syndrome. (A,B) lingual hamartoma (arrow), missed median cleft upper lip. (C,D,E) Meso- and post-axial polydactyly. (Author's own patients, reproduced with permission). 
cell apoptosis and blocks ribosomal biogenesis. This interesting phenomenon occurs singularly in cranial neural crest cells which causes a tissue specific craniofacial phenotype, illustrating the tissue specific and dosage dependent effects of a generalized disruptor. Blocking DDX21 re-localization can help rescue the craniofacial dysmorphology in Treacher Collins syndrome (Calo et al., 2018). DDX21 is also important in blood formation and its nucleolar relocalization is associated with the very rare Diamond-Blackfan syndrome causing severe anaemia due to red cell aplasia.

Another rare acro-facial dysostosis that mimics the facial features of Treacher Collins syndrome is Nager syndrome MIM\#154400. Both Nager and the extremely rare Rodriguez syndromes are caused by autosomal dominant mutations or haploinsufficiency in SF3B4 gene. SF3B4 protein belongs to the family of splicesosomes that exclude introns and ligate exons in mRNA splicing. Other craniofacial disorders caused by heterozygous mutations in splicesosomal genes include mandibulofacial dysostosis type Guion-Almeida (MFDGA) MIM\#610536 and cerebro-costo-mandibular syndrome (CCMS) MIM\#117650 (Lehalle et al., 2015).

\section{External ear}

As alluded to previously, the auricle or pinna in humans begins with formation of six mesenchymal hillocks (between $40-45^{\text {th }}$ day of embryonic life). The first three arise from the mandibular or first branchial arch and the last three from the hyoid or second branchial arch. Fusion and patterning of these six protuberances forms the pinna over the next two months. Preauricular skin tags are embryological outgrowths from the mandibular groove of the first branchial arch (Bartel-Friedrich, 2007). Around the $6^{\text {th }}$ week of gestation, migration of the hyoid mandibular arch laterally towards the cheek occurs with dynamic facial growth. This causes ear tags to be located in the line connecting the ear and the angle of the mouth. If these tags are associated with facial asymmetry, eye and cervical vertebral anomalies, it is known as Goldenhar syndrome MIM\%164210 (also called oculo-auriculo-vertebral spectrum OAVS). Although OAVS is a sporadic defect in the majority of affected individuals, familial occurrences are reported and follow an autosomal dominant inheritance pattern. Recent studies have identified a small number of OAV cases with a heterozygous variant in MYT1 gene (Lopez et al., 2016; Berenguer et al., 2017). The overexpression of MYT1 is known to cause a downstream effect in the retinoic acid metabolism. Defects in the retinoic acid (Vita$\min$ A) pathway are also responsible for cranio-facial anomalies mimicking OAVS.

Absence or underdevelopment of the auricle/pinna and the external auditory canal (EAC) is known as microtia or anotia. It usually affects males $(3: 1)$, is unilateral $(70-90 \%)$ and right-sided $(60 \%)$ (Bartel-Friedrich, 2015). Microtia is associated with syndromes in $20-60 \%$ of cases most notably OAVS and Treacher Collins syndrome and is often accompanied by conductive hearing loss (90\%). Only a few genes have been identified in the causation of isolated and syndromic microtia, of which the homeobox genes have been considered the most significant. HOXA1 and $B 1$ mutations cause anotia in mice, whereas HOXA2 mutations cause microtia in both humans and mice. Development of the early branchial protuberances are defective in HOXA2 mutants.

Methylation studies in EYA1 gene (one of the causative genes in Branchio-oto-renal syndrome) have demonstrated hypomethylation of the promoter in some individuals with microtia (Lin et al., 2009). The haploinsufficiency seen in TCOF1 gene in Treacher Collins syndrome which results in ribosome biogenesis defect is also believed to cause neural crest epithelium cell (NCC) depletion. Reduced numbers of NCC in the first and second arches may be the cause of microtia and other ear dysplasias seen in Treacher Collins syndrome. Diabetic and retinoid embryopathies are believed to follow the same mechanism in causation of external ear anomalies (Trainor, 2010). Hence, the causation of microtia is known to be influenced by chromosomal alterations, genetic variants, environmental factors including teratogens, methylation defects, ribosome biogenesis and neural crest cell insufficiency, each factor acting singly or together to cause a significant birth defect in humans (Luquetti et al., 2012). Other congenital malformations and indeed syndromes may also have similar combinatorial aetiologic mechanisms involved in their causation.

\section{Discussion}

Newer mechanistic approaches using various vertebrate and non-vertebrate animal models have been employed to learn about human craniofacial development. Both forward and reverse modelling from animal to man and the converse have been used in delineating new mutations and their role in facial formation and specific dysmorphology (Otterloo, 2016). The use of next generation sequencing (NGS) with high level phenotyping data in deciphering dysmorphic syndromes have been invaluable in understanding cranio-facial developmental pathways. Previously, many studies involving facial dysmorphology were based on observational findings in clinical situations and pattern recognition in familiar syndromes. This has now changed to reverse dysmorphology as NGS based testing is being used to identify new genes or new mutations in known genes, evolving new algorithms to describe hitherto unknown syndromes and recognizing subtler phenotypes. Newer databases compiling these data and creating consortia in craniofacial research are now emerging. One such endeavour is the Facebase consortium (Brinkley et al., 2016). However, in spite of all these resources, developing clear genotype-phenotype maps still poses the greatest challenge (Hallgrimsson, 2014).

With this body of emerging knowledge and newer molecular tools to manipulate genetic mutations in model systems, the future promises to be exciting, both in better understanding of dysmorphic genetic syndromes as well as finding the means to treat or rectify some of the serious medical or aesthetic effects of these syndromes. The complexity of processes in the formation of the face will mandate the development of mathematical algorithms incorporating data garnered from all the -omics studies, influences of the environment, age, anthropometry and ethnicity to predict "why we look as we do" (Richmond et al., 2018) and also to predict any diversions from the norm that contribute to consistent facial dysmorphology in specific syndromes.

\footnotetext{
Acknowledgements

I am grateful to be endowed with the Mazumdar-Shaw Research Chair at the Centre for Human Genetics, Bengaluru which has encouraged me to enhance the scope of my work in the field of dysmorphology and rare diseases.
} 


\section{References}

ADHIKARI K, FUENTES-GUAJARDO M, QUINTO-SÁNCHEZ M, MENDOZAREVILLA J, CAMILO CHACÓN-DUQUE J, ACUÑA-ALONZO V, JARAMILLO C, ARIAS W, LOZANO RB, PÉREZ GM, et al.,2 (016). A genome-wide association scan implicates DCHS2, RUNX2, GLI3, PAX1 and EDAR in human facial variation. Nat Commun 7: 11616

BARIK M, BAJPAI M, MALHOTRAA, SAMANTARAY JC, DWIVEDI S, DAS S (2018). Genome-Wide Association Study in Craniosynostosis Condition Using Innovative Systematic Bioinformatic Analysis Tools and Techniques: Future Prospective and Clinical Practice. J Pediatr Neurosci 13: 170-175

BARTEL-FRIEDRICH S (2015). Congenital Auricular Malformations: Description of Anomalies and Syndromes. Facial Plast Surg 31: 567-580.

BARTEL-FRIEDRICH S, WULKE C. (2007). Classification and diagnosis of ear malformations. GMS Curr Top Otorhinolaryngol Head Neck Surg 6: Doc05.

BELLDM, LEUNG KKH, WHEATLEY SC, NG LJ, ZHOU S etal., (1997). SOX9 directly regulates the type-Il collagen gene. Nat Genet 16: 174-178.

BERENGUER M, TINGAUD-SEQUEIRA A, COLOVATI M, MELARAGNO MI, BRAGAGNOLO S, PEREZ ABA, ARVEILER B, LACOMBE D, ROORYCK C, et al., (2017). A novel de novo mutation in MYT1, the unique OAVS gene identified so far. Eur J Hum Genet 25: 1083-1086.

BRINKLEY JF, FISHER S, HARRIS MP, HOLMES G, HOOPER JE, JABS EW, JONES KL, KESSELMAN C, KLEIN OD, MAAS RL, et al., (2016). The FaceBase Consortium: a comprehensive resource for craniofacial researchers. Development 143: 2677-2688.

BRUEL AL, FRANCO B, DUFFOURD Y, THEVENON J, JEGO L, LOPEZ E, DELEUZE JF, DOUMMAR D, GILES RH, JOHNSON CA, et al., (2017). Fifteen years of research on oral-facial-digital syndromes: from 1 to 16 causal genes. $J$ Med Genet 54: 371-380.

BRUGMANN SA, ALLEN NC, JAMES AW, MEKONNEN Z, MADAN E, HELMS JA. (2010). A primary cilia-dependent etiology for midline facial disorders. Hum Mol Genet 19: 1577-1592.

CALO E, GU B, BOWEN ME, ARYAN F, ZALC A, LIANG J, FLYNN RA, SWIGUT T, CHANG HY, ATTARDILD, WYSOCKAJ, (2018). Tissue-selective effects of nucleolar stress and rDNA damage in developmental disorders. Nature 554: 112-117.

CHANG HR, CHO SY, Lee JH, SEO J, CAVALCANTI DP, MAKITIE O, VALTA H, GIRISHA KM, LEE C, NEETHUKRISHNA K, BHAVANI GS, SHUKLA A, NAMPOOTHIRI S, PHADKE SR et al.,2019) Hypomorphic Mutations in TONSL Cause SPONASTRIME Dysplasia. Am J Hum Genet 104: 439-453.

CLAES P, SHRIVER MD, (2014). Establishing a multidisciplinary context for modeling 3D facial shape from DNA. PLoS Genet 10: e1004725.

COLLINS, E. T, (1933). Cases with symmetrical congenital notches in the outer part of each lower lid and defective development of the malar bones. Trans Ophthal Soc UK 20: 190-192

DALAL AB, PHADKE SR, (2007). Morphometric analysis of face in dysmorphology. Comput Methods Programs Biomed 85: 165-172.

DEVII, (1959). Study on the genetics of human eye-brows. Am J Hum Genet 11:35-51.

DONNAI D, (2009). Advances in dysmorphology: from diagnosis to treatment. Clin Med (Lond) 9: 154-155.

DUDDING-BYTHT, BAXTERA, HOLLIDAYEG, HACKETTA, O'DONNELLS, WHITE SM, ATTIA J, BRUNNER H, DE VRIES B KOOLEN D, et al., (2017). Computer face-matching technology using two-dimensional photographs accurately matches the facial gestalt of unrelated individuals with the same syndromic form of intellectual disability. BMC Biotechnol 17: 90.

FADZILAH N, AZMAN M, SEE GB, (2016). Congenital Midline Tongue Base Mass in An Infant: Lingual Hamartoma. J Clin Diagn Res 10: MD01-MD03.

GOOS JAC and MATHIJSSEN IMJ, (2019). Genetic Causes of Craniosynostosis: An Update. Mol Syndromol 10: 6-23.

GUROVICH Y, HANANI Y, BAR O, NADAV G, FLEISCHER N, GELBMAN D, BASELSALMON L, KRAWITZ PM, KAMPHAUSEN SB, ZENKER M, BIRD LM, GRIPP $\mathrm{KW}$, (2019). Identifying facial phenotypes of genetic disorders using deep learning. Nat Med 25: 60-64.

HALLGRIMSSONB, MIOW, MARCUCIO RS, SPRITZR, (2014). Let's face it--complex traits are just not that simple. PLoS Genet 10: e1004724.

HAMMOND P, HUTTONTJ, ALLANSON JE, BUXTON B, CAMPBELLLE, CLAYTON-
SMITH J, DONNAI D, KARMILOFF-SMITH A, METCALFE K, MURPHY KC, et al., (2005). Discriminating power of localized three-dimensional facial morphology. Am J Hum Genet 77: 999-1010.

HARIKRISHNAN P, BALAKUMARAN V, (2018). Analysis of Intramaxillary and MidFace Skeletal Asymmetry in a Three-Dimensional Model with Complete Unilateral Cleft Lip and Palate. J Craniofac Surg 29: e759-e762

HAWASS Z, GAD YZ, ISMAIL S, KHAIRAT R, FATHALLA D, HASAN N, AHMED A, ELLEITHY H, BALL M, GABALLAH F, et al., (2010). Ancestry and pathology in King Tutankhamun's family. JAMA 303: 638-647.

HTTPS://www.face2gene.com/lmd-library-london-medical-database-dysmorphology/ HTTPS://www.possum.net.au/

JAKOBSEN LP, ULLMANN R, CHRISTENSEN SB, JENSEN KE, MØLSTED K HENRIKSEN KF, HANSEN C, KNUDSEN MA, LARSEN LA, TOMMERUP N, TÜMER Z, (2007). Pierre Robin sequence may be caused by dysregulation of SOX9 and KCNJ2. J Med Genet 44: 381-386.

JUGESSUR A1, SHI M, GJESSING HK, LIE RT, WILCOX AJ, WEINBERG CR, CHRISTENSEN K, BOYLES AL, DAACK-HIRSCH S, TRUNG TN, et al. (2009). Genetic determinants of facial clefting: analysis of 357 candidate genes using two national cleft studies from Scandinavia. PLoS One 4: e5385.

KONDO S, SCHUTTE BC, RICHARDSON RJ, BJORK BC, KNIGHTAS, WATANABE Y, HOWARD E, DE LIMA RL, DAACK-HIRSCH S, SANDER A, et al. (2002). Mutations in IRF6 cause Van der Woude and popliteal pterygium syndromes. Nat Genet 32: 285-289.

KUMAR P, (2017). Synophrys: Epidemiological Study. Int J Trichology 9: 105-107.

LATTANZI W, BARBA M, DI PIETRO L, BOYADJIEV SA, (2017). Genetic advances in craniosynostosis. Am J Med Genet A 173: 1406-1429.

LEHALLE D, WIECZOREK D, ZECHI-CEIDE RM, PASSOS-BUENO MR, LYONNET S, AMEIL J, GORDON CT, (2015). A review of craniofacial disorders caused by splicesosomal defects. Clin Genet 88: 405-415.

LE PABIC P, NG C, SCHILLING TF, (2014). Fat-Dachsous signaling coordinates cartilage differentiation and polarity during craniofacial development. PLOS Genet10: e1004726

LIN L, PAN B, JIANG HY, ZHUANG HX, ZHAO YY, YANG QH, HE LR, HAN J, WANG SJ, (2009). Study of methylation of promoter of EYA1 gene in microtia. Zhonghua Zheng Xing Wai Ke Za Zhi 25: 436-439.

LIU X-Z, NEWTON VE, READ AP, (1995). Waardenburg syndrome type II: phenotypic findings and diagnostic criteria. Am J Med Genet 55: 95-100.

LOOTS GG, KNEISSEL M, KELLER H, BAPTIST M, CHANG J, COLLETTE NM, OVCHARENKO D, PLAJZER-FRICK I, RUBIN EM, (2005). Genomic deletion of a long-range bone enhancer misregulates sclerostin in Van Buchem disease. Genome Res 15: 928-935.

LOPEZ E, BERENGUER M, TINGAUD-SEQUEIRA A, MARLIN S, TOUTAIN A DENOYELLE F, PICARD A, CHARRON S, MATHIEU G, DE BELVALET H, et al., (2016). Mutations in MYT1, encoding the myelin transcription factor 1 , are a rare cause of OAVS. J Med Genet 53: 752-760.

LUQUETTI DV, HEIKE CL, HING AV, CUNNINGHAM ML, COX TC, (2012). Microtia: epidemiology and genetics. Am J Med Genet A 158A: 124-139.

MAKAROV R, STEINER B, GUCEV Z, TASIC V, WIEACKER P, WIELAND I, (2010). The impact of CFNS-causing EFNB1 mutations on ephrin-B1 function. BMC Med Genet11: 98

MARCUCIO R, HALLGRIMSSON B, YOUNG NM, (2015). Facial Morphogenesis: Physical and Molecular Interactions Between the Brain and the Face. Curr Top Dev Biol 115: 299-320.

MOSSEY PA, MODELL B, (2012). Epidemiology of oral clefts 2012: an international perspective. Front Oral Biol 16: 1-18.

MUHAMMAD UMAIR, FAROOQ AHMAD, MUHAMMAD BILAL, MUHAMMAD ARSHAD, (2018). Frontonasal dysplasia: a review. J of Biochem and Clin Genet1:2-14.

PATERNOSTER L, ZHUROV AI, TOMA AM, KEMP JP, ST POURCAIN B, TIMPSON NJ, MCMAHON G, MCARDLE W, RING SM, SMITH GD, RICHMOND S, EVANS DM, (2012). Genome-wide association study of three-dimensional facial morphology identifies a variant in PAX3 associated with nasion position. Am $J$ Hum Genet 90: 478-485.

RICHMOND S, HOWE LJ, LEWIS S, STERGIAKOULI E, ZHUROV A, (2018). Facial Genetics: A Brief Overview. Front Genet 9: 462.

ROZPRÝM F, (1934). Eyebrows and Eyelashes in Man: Their Different Forms, Pig- 
mentation and Heredity. J. Roy. Anthropol. Inst. GB Ireland 64: 353-395

SADLEIR LG, GECZ J, SCHEFFER IE, (2016) Epilepsies that occur predominantly in girls. In: Johnston MV, Adams HP, Fatemi A, (eds). Neurobiology of disease. New York: Oxford University Press; p. 307-311.

SADR J, JARUDI I, SINHA P, (2003). The role of eyebrows in face recognition. Perception 32: 285-293.

STOTTMANN RW, TURBE-DOAN A, TRAN P, KRATZ LE, MORAN JL, KELLEY RI, et al., (2011). Cholesterol Metabolism Is Required for Intracellular Hedgehog Signal Transduction In Vivo. PLoS Genet 7: e1002224.

STUPPIA L, CAPOGRECO M, MARZO G, LA ROVERE D, ANTONUCCI I, GATTA V, PALKA G, MORTELLARO C, TETÈ S, (2011). Genetics of syndromic and nonsyndromic cleft lip and palate. J Craniofac Surg 22: 1722-1726.

TIMBERLAKE AT, CHOI J, ZAIDI S, LU Q, NELSON-WILLIAMS C, BROOKS ED, BILGUVAR K, TIKHONOVA I, MANE S, YANG JF, et al., (2016). Two locus inheritance of non-syndromic midline craniosynostosis via rare SMAD6 and common BMP2 alleles. Elife 5. pii: e20125.

TRAINOR PA, (2010). Craniofacial birth defects: The role of neural crest cells in the etiology and pathogenesis of Treacher Collins syndrome and the potential for prevention. Am J Med Genet A 152A: 2984-2994.

TWIGG SR, VERSNEL SL, NÜRNBERG G, LEES MM, BHAT M, HAMMOND P, HENNEKAM RC, HOOGEBOOM AJ, HURST JA, JOHNSON D, et al. (2009). Frontorhiny, a distinctive presentation of frontonasal dysplasia caused by recessive mutations in the ALX3 homeobox gene. Am J Hum Genet 84: 698-705.

TWIGG SR, BABBS C, VAN DEN ELZEN ME, GORIELY A, TAYLOR S, MCGOWAN SJ, GIANNOULATOU E, LONIE L, RAGOUSSISJ, SADIGHIAKHAE, etal., (2013).
Cellular interference in craniofrontonasal syndrome: males mosaic for mutations in the X-linked EFNB1 gene are more severely affected than true hemizygotes. Hum Mol Genet 22: 1654-1662.

TWIGG SR and WILKIE AOM,(2015) A Genetic-Pathophysiological Framework for Craniosynostosis. Am J Hum Genet 97: 359-377.

VAN OTTERLOO E, WILLIAMS T, ARTINGER KB, (2016). The old and new face of craniofacial research: How animal models inform human craniofacial genetic and clinical data. Dev Biol 415: 171-187.

VINCENT M, GENEVIÈVE D, OSTERTAG A, MARLIN S, LACOMBE D, MARTINCOIGNARD D, COUBES C, DAVID A, LYONNET S, VILAIN C, et al., (2016). Treacher Collins syndrome: a clinical and molecular study based on a large series of patients. Genet Med 18: 49-56.

WHYTE MP, AMALNATH DS, McALISTER WH, PEDAPATI R, MUTHUPILLAI V, DUAN S, HUSKEY M, BIJANKI VN, MUMM S. (2018) Sclerosteosis: Report of type 1 or 2 in three Indian Tamil families and literature review. Bone 116: 321-332.

WILDERMAN A, VANOUDENHOVE J, KRON J, NOONAN JP, COTNEY J, (2018). High-Resolution Epigenomic Atlas of Human Embryonic Craniofacial Development. Cell Repr 23: 1581-1597.

WILKIE AOM, JOHNSON D, WALL SA, (2017). Clinical genetics of craniosynostosis. Curr Opin Pediatr 29: 622-628.

WU E, VARGEVIK K, SLAVOTINEK AM, (2007). Subtypes of frontonasal dysplasia are useful in determining clinical prognosis. Am J Med Genet A 143A: 3069-3078.

YASSINE NM, SHAHRAM JT and BODY SC, (2017) Pathogenic Mechanisms of Bicuspid Aortic Valve Aortopathy. Front Physiol 8: 687 


\section{Further Related Reading, published previously in the Int. J. Dev. Biol.}

Migration of lymphatic endothelial cells and lymphatic vascular development in the craniofacial region of embryonic mice Yuji Taya, Kaori Sato, Youichi Shirako and Yuuichi Soeno

Int. J. Dev. Biol. (2018) 62: 293-301

https://doi.org/10.1387/ijdb.170218yt

Craniofacial development: discoveries made in the chicken embryo

John Abramyan and Joy M. Richman

Int. J. Dev. Biol. (2018) 62: 97-107

https://doi.org/10.1387/ijdb.170321ja

Specification of sensory placode progenitors: signals and transcription factor networks Andrea Streit

Int. J. Dev. Biol. (2018) 62: 195-205

https://doi.org/10.1387/ijdb.170298as

Bone morphogenetic protein 4 promotes craniofacial neural crest induction from human pluripotent stem cells Sumiyo Mimura, Mika Suga, Kaori Okada, Masaki Kinehara, Hiroki Nikawa and Miho K. Furue Int. J. Dev. Biol. (2016) 60: 21-28

https://doi.org/10.1387/ijdb.160040mk

Molecular signaling at the fusion stage of the mouse mandibular arch: involvement of insulin-like growth factor family

Kazuya Fujita, Yuji Taya, Yoshihito Shimazu, Takaaki Aoba and Yuuichi Soeno

Int. J. Dev. Biol. (2013) 57: 399-406

https://doi.org/10.1387/ijdb.120110ys

Essential role of AWP1 in neural crest specification in Xenopus

Jeong-Han Seo, Dong-Seok Park, Mina Hong, Eun-Ju Chang and Sun-Cheol Choi

Int. J. Dev. Biol. (2013) 57: 829-836

https://doi.org/10.1387/ijdb.130109sc

Contribution of mesoderm to the developing dental papilla

Michaela Rothová, Jifan Feng, Paul T. Sharpe, Renata Peterková and Abigail S. Tucker

Int. J. Dev. Biol. (2011) 55: 59-64

https://doi.org/10.1387/ijdb.103083mr

Expression of Wnts in the developing murine secondary palate

Dennis R. Warner, Henry S. Smith, Cynthia L. Webb, Robert M. Greene and M. Michele Pisano

Int. J. Dev. Biol. (2009) 53: 1105-1112

https://doi.org/10.1387/ijdb.082578dw
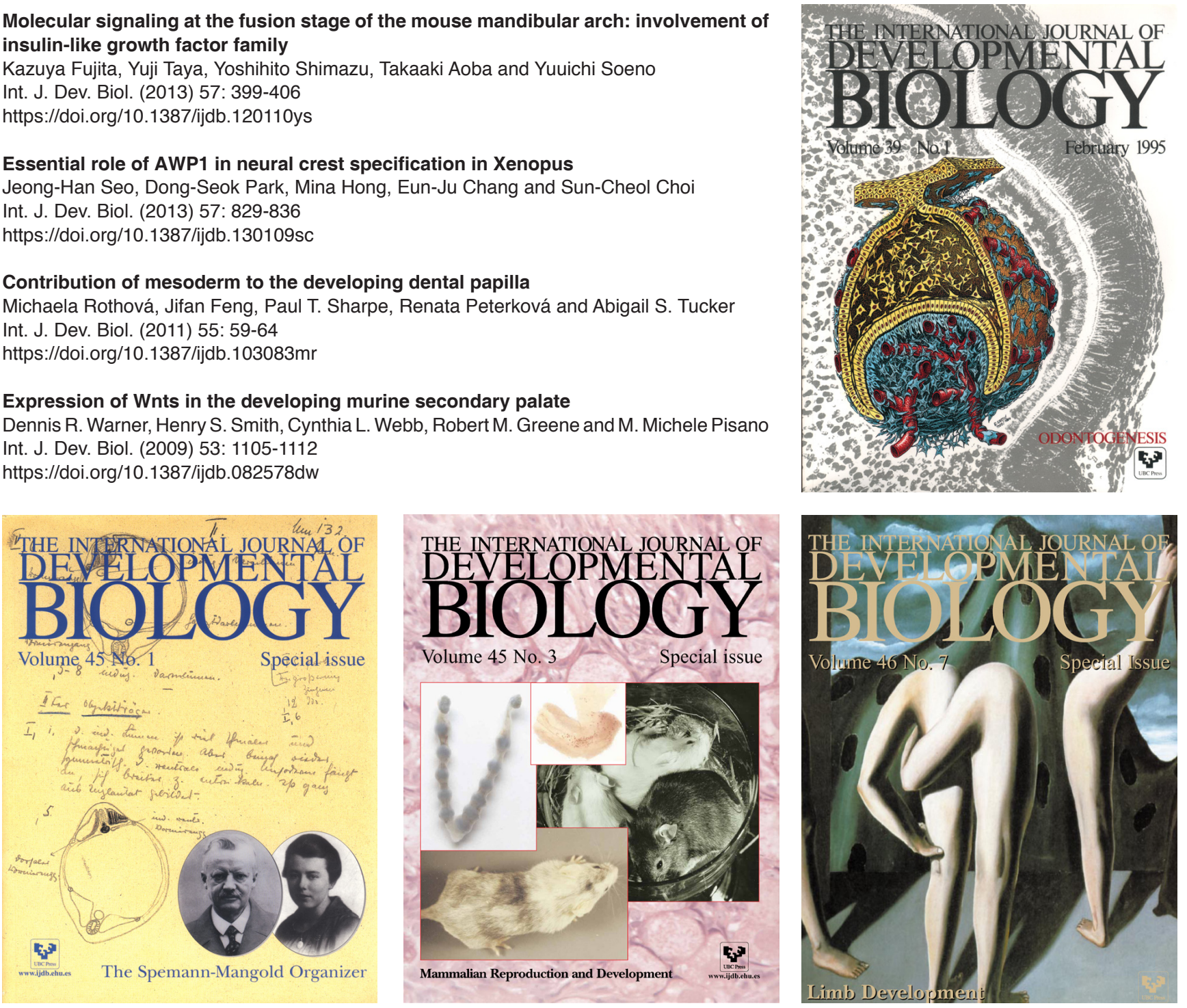